\title{
Glycemic control and cost-effectiveness attained by the drug utilization of oral antidiabetic agents in a tertiary care hospital in South India
}

\author{
Nirmal George ${ }^{1}$, Ajith Kumar PV ${ }^{2}$, Vijayalekshmi Amma S. ${ }^{1 *}$
}

\begin{abstract}
${ }^{1}$ Department of Pharmacology,
${ }^{2}$ Department of Diabetology, Sree Gokulam Medical College, Venjaramoodu, Trivandrum, India
\end{abstract}

Received: 11 January 2016

Revised: 03 March 2016

Accepted: 15 March 2016

\section{*Correspondence to: \\ Dr. Vijayalekshmi Amma S., Email: vijayalekshmiammas1 @ gmail.com}

Copyright: (C) the author(s), publisher and licensee Medip Academy. This is an openaccess article distributed under the terms of the Creative Commons Attribution NonCommercial License, which permits unrestricted noncommercial use, distribution, and reproduction in any medium, provided the original work is properly cited.

\begin{abstract}
Background: Diabetes mellitus require lifelong intervention and Kerala has high prevalence. New expensive agents require comparison with existing regimens for cost-effectiveness.

Methods: Socio-demographic, anthropometric, FPG and HbA1C (baseline and post treatment) of 150 patients ( 73 men; 77 women) were obtained from records using standard case report forms in our retrospective study. ANOVA and paired $t$ test were used for between groups and within group comparison.

Results: Metformin was maximum utilized (DDD/1000/day-252.39). All treatment regimens produced significant reduction in FPG (except metformin monotherapy) and $\mathrm{HbA1C}$ (except metformin sulfonylurea $\alpha$-glucosidase inhibitor DPP-4 inhibitor combination). When compared to metformin sulfonylurea pioglitazone combination (best therapy), other regimens were less cost effective in reducing FPG and metformin sulfonylurea $\alpha$-glucosidase inhibitor DPP-4 inhibitor was more effective and expensive in reducing HbA1C.

Conclusions: High prescription rates of metformin were due to its action on insulin resistance and weight. Addition of pioglitazone was cost effective and DPP-4 inhibitor was expensive but effective.
\end{abstract}

Keywords: ATC/DDD antidiabetic agent's cost-effectiveness analysis pioglitazone DPP-4 inhibitors

\section{INTRODUCTION}

Diabetes mellitus is a pandemic non communicable disease. India is often quoted as the 'diabetes capital of the world'. ' though we do not have the largest population of diabetics or the highest prevalence of diabetes. ${ }^{2}$ Reports of high prevalence of diabetes in south India dates back to the year 2000. The highest prevalence of diabetes reported so far from India has been from Ernakulum, where a prevalence of diabetes was $19.5 \% .^{3}$ and a prevalence of type 2 diabetes mellitus (T2DM) of $16.3 \%$ has also been reported from Trivandrum. ${ }^{4}$ Life long lifestyle modifications and medications are required for maintaining glycemic control in diabetics, which signifies the importance of knowledge about costeffectiveness, hence this study. Pharmacoepidemiology is a discipline which is defined as the study of use of and the effect of drugs in large population. ${ }^{5}$ Drug utilization studies are integral part of Pharmacoepidemiology. It describes the nature, determinants and extent of drug exposure and is powerful exploratory tools to ascertain the role of drugs in society. ${ }^{6}$ They also assess the rationality of prescriptions, provide feedback and create awareness among prescribers. Prescription analysis can also be done according to WHO specified drug use indicators which can be used to assess the extent of drug use, which is expected to be appropriate, economical, safe, effective and according to treatment guidelines in a tertiary care teaching hospital.

The objectives of this study was to determine the drug utilization pattern, glycemic control and cost- 
effectiveness of oral antidiabetic agents prescribed at diabetology outpatient of Sree Gokulam medical college and research foundation, Venjaramoodu, Trivandrum, India.

\section{METHODS}

Our study is a record based retrospective study of 150 T2DM patients diagnosed and treated by diabetologist for more than 6 months were analysed. Sample size was calculated by assuming $\alpha$ as 0.05 and $\beta$ as 0.2 and a power of $80 \%$. Patients who attended the diabetology outpatient between $1^{\text {st }}$ December 2012 and $1^{\text {st }}$ December 2013 were included in the study. Newly detected diabetics, patients on insulin and those who had a regimen change in the study period were excluded from the study. Institutional ethics committee clearance was obtained prior to commencing the study and written informed consent was waivered since no intervention was done, identifying details of patients were not collected and there was no direct patient interaction. Two values of fasting plasma glucose (FPG) and glycated haemoglobin (HbA1C), pre-treatment and one year post treatment were obtained from medical records of the patients enrolled along with co-morbidities, co-prescribed medications, antidiabetic agents used, socio-demographic, anthropometric data in standard case record form. Defined daily dose (DDD) for each drug was obtained from WHO ATC index, DDD/1000/day and prescribed daily dose (PDD) was calculated using the formula 1 and 2 respectively. ${ }^{6,7}$

1. Total number of dosage units prescribed $x$ strength of each dosage unit $\times 1000$ $\mathrm{DDD} \times$ Duration of study $\times$ total sample size. ${ }^{6}$

2. Total number of dosage unitsprescribed $\times$ strength of each dosage unit Number of patients who were prescribed the medication?

Cost, strength and composition of brands of medicines were obtained from www.cimsasia.com. Costeffectiveness analysis was done for five most frequently prescribed treatment regimens. Average costeffectiveness ratio (ACER) was calculated by dividing the cost of treatment regimen per day by difference produced by treatment in the health outcome. Incremental cost-effectiveness ratio (ICER) was calculated using the formula by considering one treatment regimen as the best treatment. $^{8}$

\section{[Costof dingA-Cost of thig B]}

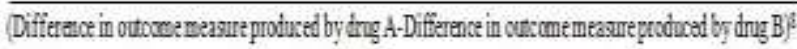

Where $\mathrm{A}$ is the assumed best treatment regimen and $\mathrm{B}$ other treatment regimens.
Statistical analysis was done using $\mathrm{R}$ software ${ }^{\circledR}$ using descriptive statistics. Values are expressed as mean \pm standard error of mean and rounded off to single decimal. Between group comparisons of baseline characteristics, reduction in FPG and $\mathrm{HbA} 1 \mathrm{C}$ was done using ANOVA and paired $t$ test was used for within group comparison of FPG and HbA1C. A p value $<0.05$ was considered statistically significant. Incremental costeffectiveness plots were obtained from http://www.healthstrategy.com.

\section{RESULTS}

1044 prescriptions of patients in the age range of 28 to 83 were analysed. Average number of prescriptions were per patient per year was 6.96. The mean BMI, age and duration of diabetes were $24.6 \pm 0.2 \mathrm{~kg} / \mathrm{m}^{2}, 55.1 \pm 0.8$ years and $5.3 \pm 0.4$ years respectively. There was no significant difference in baseline characteristics of the patients included in the study (Table 1).

Table1: Baseline characteristics of T2DM patients.

\begin{tabular}{|lllll|}
\hline Gender & $\mathbf{n}(\%)$ & $\begin{array}{l}\text { BMI } \\
\left(\mathbf{k g} / \mathbf{m}^{2}\right)\end{array}$ & $\begin{array}{l}\text { Age } \\
(\text { years })\end{array}$ & $\begin{array}{l}\text { Duration of } \\
\text { diabetes } \\
\text { (years) }\end{array}$ \\
\hline Female & $\begin{array}{l}77 \\
(51.3 \%)\end{array}$ & $24.9 \pm 0.3$ & $\begin{array}{l}54.5 \pm 1 . \\
1\end{array}$ & $4.9 \pm 0.5$ \\
\hline Male & $\begin{array}{l}73 \\
(48.7 \%)\end{array}$ & $24.4 \pm 0.3$ & $\begin{array}{l}55.6 \pm 1 . \\
3\end{array}$ & $5.6 \pm 0.6$ \\
\hline
\end{tabular}

Prescription pattern analysis showed the average number of antidiabetic agent prescribed per patient was 2.2 \pm 0.1 . Combination therapy $(n=111)$ was preferred over monotherapy $(n=39)$ of which dual antidiabetic agents $(n=55)$ were preferred. Three and four antidiabetic agents were prescribed for 43 and 13 patients respectively. Among the monotherapy agents metformin $(n=34)$ was the prescribers favourite followed by sulfonylurea $(n=4)$ and DPP-4 inhibitors $(n=1)$. Antidiabetic agents prescribed in the decreasing order of frequency were metformin ( $n=143)$, sulfonylurea $(n=99)$, $\alpha$-glucosidase inhibitors $(n=42)$, DPP-4 inhibitors $(n=24)$ and pioglitazone $(n=16)$. Among the sulfonylureas, the use of glimepiride $(n=73)$ was favoured, glibenclamide $(n=16)$, gliclazide $(n=7)$, glipizide $(n=3)$ were infrequent used. Among the 42 prescriptions for $\alpha$-glucosidase inhibitors 41 were of voglibose 1 was acarbose and miglitol was not prescribed. Vildaglipitn $(n=23)$ and sitaglipitin $(n=1)$ were the prescribed DPP-4 inhibitors.

The most frequently used treatment regimen (Table 2) was metformin sulfonylurea combination $(n=46)$, of which 33 patients were prescribed metformin glimepiride combination. Other frequent treatment regimens were metformin monotherapy $(n=34)$ and combinations of metformin sulfonylurea $\alpha$-glucosidase inhibitor $(n=24)$, metformin sulfonyl urea pioglitazone $(n=8)$ and metformin sulfonylurea $\alpha$-glucosidase inhibitor DPP-4 inhibitor $(n=8)$. Infrequent regimens $(n=30)$ included 
monotherapy with agents other than metformin and various other combinations of these agents. Drug utilization (Table 3) as per defined daily dose (DDD/1000/day) showed metformin (DDD/1000/day 252.4) as the most utilized. Other highly utilized agents were glimepiride (215.3), vildaglipitn (40.1), gliclazide (32.5) and pioglitazone (31.6). Sitagliptin (3.1) and acarbose (0.5) were the least utilized. Prescribed daily dose were lower than DDD for all agents except gliclazide and acarbose which were prescribed at higher doses and sitagliptin similar dose as DDD.

Table 2: Treatment regimens of T2DM patients.

\begin{tabular}{|ll|}
\hline Treatment regimens & n $(\%)$ \\
\hline MET+SU & $46(30.7 \%)$ \\
\hline MET & $34(22.7 \%)$ \\
\hline MET+SU+AGI & $24(16 \%)$ \\
\hline MET+SU+PIO & $8(5.3 \%)$ \\
\hline MET+SU+AGI+DPP-4 I & $8(5.3 \%)$ \\
\hline Other regimens & $30(20 \%)$ \\
\hline $\begin{array}{l}\text { Met-metformin, SU-sulfonylurea, AGI- } \alpha \text { glucosidase } \\
\text { inhibitor, PIO-pioglitazone, DPP -4 I-dipeptidyl peptidase-4 } \\
\text { inhibitor. }\end{array}$
\end{tabular}

Five most frequently prescribed treatment regimens were analysed for baseline variability (Table 4). Metformin sulfonylurea $\alpha$-glucosidase inhibitor combination and metformin sulfonylurea pioglitazone combination had significant longer duration of diabetes compared to metformin monotherapy. Pre-treatment HbA1C showed statistically significant lower value for metformin monotherapy. No other differences were observed between groups.

All groups except metformin monotherapy showed significant reduction in FPG and all groups except metformin sulfonylurea pioglitazone combination showed significant reduction in $\mathrm{HbA1C}$ when compared using 'paired t test' (Table 5 and Figure 1,2). Between groups, comparison of reduction of $\mathrm{HbA} 1 \mathrm{C}$ showed no significant difference hence reduction in FPG and proportion of patients attaining ADA glycemic goal $(\mathrm{HbA} 1 \mathrm{C}<7)$ was used to determine the best treatment regimen for incremental cost effectiveness ratio (ICER). Metformin sulfonylurea pioglitazone combination produced significant reduction in FPG compared to 3 other groups and had the maximum proportion of patients attaining ADA goal for diabetics (50\%). Least proportion of patients attaining ADA goal was under metformin sulfonylurea $\alpha$-glucosidase inhibitor DPP-4 inhibitor combination regimen.

Table3: DDD/1000/day and prescribed daily dose (PDD) of various antidiabetic agents.

\begin{tabular}{|lllll|}
\hline Antidiabetic agent & ATC code & Defined daily dose (DDD) & DDD/1000 /day & Prescribed daily dose (PDD) \\
\hline Metformin & A10BA02 & $2 \mathrm{~g}$ & 252.4 & $1.1 \pm 0.1 \mathrm{gm} / \mathrm{user} / \mathrm{day}$ \\
\hline Glimepiride & A10BB12 & $2 \mathrm{mg}$ & 215.3 & $1.9 \pm 0.1 \mathrm{mg} / \mathrm{user} / \mathrm{day}$ \\
\hline Vildagliptin & A10BH02 & $0.1 \mathrm{~g}$ & 40.1 & $56.5 \pm 4.2 \mathrm{mg} / \mathrm{user} / \mathrm{day}$ \\
\hline Gliclazide & A10BB09 & $60 \mathrm{mg}$ & 32.5 & $90.3 \pm 13.3 \mathrm{mg} / \mathrm{user} / \mathrm{day}$ \\
\hline Pioglitazone & A10BG03 & $30 \mathrm{mg}$ & 31.6 & $19.2 \pm 2.4 \mathrm{mg} / \mathrm{user} / \mathrm{day}$ \\
\hline Glibenclamide & A10BB01 & $7 \mathrm{mg}$ & 15.9 & $2.2 \pm 0.1 \mathrm{mg} / \mathrm{user} / \mathrm{day}$ \\
\hline Glipizide & A10BB07 & $10 \mathrm{mg}$ & 7.7 & $8.3 \pm 1.7 \mathrm{mg} / \mathrm{user} / \mathrm{day}$ \\
\hline Sitagliptin & A10BH01 & $0.1 \mathrm{~g}$ & 3.1 & $100 \mathrm{mg} / \mathrm{user} / \mathrm{day}$ \\
\hline Acarbose & A10BF01 & $0.3 \mathrm{~g}$ & 0.5 & $50 \mathrm{mg} / \mathrm{user} / \mathrm{day}$ \\
\hline Voglibose & A10BF03 & $-*$ & & $0.4 \pm 0.03 \mathrm{mg} / \mathrm{user} / \mathrm{day}$ \\
\hline
\end{tabular}

* DDD not defined by ATC index

Table 4: Baseline characteristics of patients in frequently prescribed treatment regimens.

\begin{tabular}{|llllll|}
\hline Regimen (n) & $\begin{array}{l}\text { Age } \\
\text { (years) }\end{array}$ & $\begin{array}{l}\text { BMI } \\
(\mathrm{kg} / \mathrm{m} 2)\end{array}$ & $\begin{array}{l}\text { Duration of } \\
\text { diabetes (years) }\end{array}$ & $\begin{array}{l}\text { Pre-treatment } \\
\text { FPG }\end{array}$ & $\begin{array}{l}\text { Pre-treatment } \\
\text { HbA1C }\end{array}$ \\
\hline MET $(\mathrm{n}=34)$ & $50.4 \pm 1.8$ & $24.5 \pm 0.4$ & $3.0 \pm 0.5$ & $145.1 \pm 6.1$ & $7.3 \pm 0.2 * *$ \\
\hline MET+SU $(\mathrm{n}=46)$ & $56.6 \pm 1.5$ & $24.7 \pm 0.4$ & $4.96 \pm 0.7$ & $147.2 \pm 6.4$ & $7.6 \pm 0.2$ \\
\hline MET+SU+AGI $(\mathrm{n}=24)$ & $58.2 \pm 1.8$ & $23.9 \pm .5$ & $7.1 \pm 1.3 *$ & $145.5 \pm 8.2$ & $7.8 \pm 0.3$ \\
\hline MET+SU+PIO (n=8) & $54.8 \pm 2.4$ & $25.8 \pm 1.2$ & $8.4 \pm 1.2 *$ & $188.3 \pm 21.5$ & $7.5 \pm 0.5$ \\
\hline MET+SU+AGI+ DPP-4 I $(\mathrm{n}=8)$ & $56.4 \pm 3.1$ & $24.9 \pm 1.3$ & $5.3 \pm 1.2$ & $140.6 \pm 13.4$ & $7.8 \pm 0.2$ \\
\hline
\end{tabular}

MET- metformin; SU- sulfonylurea, AGI- $\alpha$-glucosidase inhibitor; PIO- pioglitazone; DPP -4I- dipeptidyl peptidase - 4 inhibitor

*indicates statistically significant higher value using ANOVA compared to metformin group; ** indicates statistically significant lower value using ANOVA compared to other groups. 
Mean cost of medications per patient per year was 9293.1 \pm 483.6 INR, of which cost of antidiabetic agents were $5053.7 \pm 371.8$ INR and cost of co-prescribed medications were $4310.3 \pm 338.5$ INR. Metformin monotherapy was the most economic treatment. Average cost-effectiveness ratio for unit reduction in FPG and HbA1C per day was 20 paisa and 6 INR respectively for metformin monotherapy and, 11 paisa and 39 INR respectively for metformin sulfonylurea combination. Most effective treatment regimen according to our study, metformin sulfonylurea pioglitazone combination showed an average cost of 1 and 121 INR for unit reduction of FPG and HbA1C. Newest member, DPP-4 inhibitors proved to be effective in controlling blood glucose when combined with other medications but was found to be expensive (7.2 and 752.88 INR for unit reduction of FPG and HbA1C). Incremental cost-effectiveness ratio (ICER) (Table 6 and Figure 3,4) in reducing FPG, considering metformin sulfonylurea pioglitazone as best treatment regimen, showed that metformin sulfonylurea $\alpha$-glucosidase inhibitor DPP-4 inhibitor combination as less effective and more expensive. All the other treatment regimens are less effective and less expensive. ICER for reduction in HbA1C (considering metformin sulfonylurea pioglitazone as best treatment) showed all treatment regimens were less costly and less expensive except metformin sulfonylurea $\alpha$ glucosidase inhibitor DPP-4 inhibitor combination which is more effective and more expensive.

Table 5: Comparison of FPG and HbA1C pre-treatment and 1 year post treatment.

\begin{tabular}{|c|c|c|c|c|c|c|c|}
\hline \multirow[t]{2}{*}{ Regimen (n) } & \multicolumn{3}{|l|}{ FPG (mg/dl) } & \multicolumn{2}{|l|}{ HbA1C (\%) } & \multicolumn{2}{|c|}{$\begin{array}{l}\text { Proportion of } \\
\text { patients attaining } \\
\text { HbA1C }<7\end{array}$} \\
\hline & Pre-treatment & $\begin{array}{l}\text { Post- } \\
\text { treatment }\end{array}$ & Reduction & Pre-treatment & $\begin{array}{l}\text { Post- } \\
\text { treatment }\end{array}$ & Reduction & \\
\hline $\mathrm{MET}^{34}$ & $145.1 \pm 6.3$ & $\begin{array}{l}135.8 \pm 4 \\
(p=0.081)\end{array}$ & $22.98 \pm 3.8$ & $7.3 \pm 0.2^{* * *}$ & $\begin{array}{l}6.8 \pm 0.1^{*} \\
(p<0.01)\end{array}$ & $0.6 \pm 0.1$ & $14(41.2 \%)$ \\
\hline $\mathrm{MET}+\mathrm{SU}^{46}$ & $147.2 \pm 6.4$ & $\begin{array}{l}129 \pm 3.8^{*} \\
(p<0.05)\end{array}$ & $20.2 \pm 6.6$ & $7.6 \pm 0.2$ & $\begin{array}{l}7.1 \pm 0.1^{*} \\
(p<0.01)\end{array}$ & $0.6 \pm 0.1$ & $19(41.3 \%)$ \\
\hline $\mathrm{MET}+\mathrm{SU}+\mathrm{AGI}^{24}$ & $145.5 \pm 8.2$ & $\begin{array}{l}124.1 \pm 3.7^{*} \\
(\mathrm{p}<0.01)\end{array}$ & $21.4 \pm 6.9$ & $7.8 \pm 0.3$ & $\begin{array}{l}7.2 \pm 0.2^{*} \\
(p<0.01)\end{array}$ & $0.6 \pm 0.2$ & $11(45.8 \%)$ \\
\hline $\mathrm{MET}+\mathrm{SU}+\mathrm{PIO}^{8}$ & $188.3 \pm 21.5$ & $\begin{array}{l}117.3 \pm 5.9^{*} \\
(p<0.05)\end{array}$ & $71 \pm 23.6^{* *}$ & $7.5 \pm 0.5$ & $\begin{array}{l}6.8 \pm 0.2 \\
(p=0.1)\end{array}$ & $0.7 \pm 0.4$ & $4(50 \%)$ \\
\hline $\begin{array}{l}\mathrm{MET}+\mathrm{SU}+\mathrm{AGI} \\
+\mathrm{DPP}-4 \mathrm{I}^{8}\end{array}$ & $140.6 \pm 13.4$ & $\begin{array}{l}108.3 \pm 13.6^{*} \\
(p<0.01)\end{array}$ & $32.4 \pm 8.7$ & $7.8 \pm 0.2$ & $\begin{array}{l}6.9 \pm 0.1^{*} \\
(p<0.01)\end{array}$ & $0.9 \pm 0.2$ & $2(25 \%)$ \\
\hline
\end{tabular}

Met-metformin; SU- sulfonylurea; AGI- $\alpha$-glucosidase inhibitor; PIO- pioglitazone; DPP -4 I- dipeptidyl peptidase - 4 inhibitor; *indicates significant reduction in post treatment value by paired t test $(\mathrm{p}<0.05)$; ** indicates significant reduction in FPG when compared to other groups by ANOVA $(\mathrm{p}<0.05)$; $* * *$ indicates significant lower pre-treatment value compared to other groups by ANOVA $(\mathrm{p}<0.05)$.

Table 6: Cost-effectiveness of various treatment regimens.

\begin{tabular}{|lllll|}
\hline Regimen $(n)$ & $\begin{array}{l}\text { ICER for FPG } \\
\text { reduction } \\
\text { (INR/mg/dl/day) }\end{array}$ & $\begin{array}{l}\text { ICER for HbA1C } \\
\text { reduction } \\
\text { (INR/\%/day) }\end{array}$ & $\begin{array}{l}\text { ACER for FPG } \\
\text { reduction } \\
\text { (INR/mg/dl/day) }\end{array}$ & $\begin{array}{l}\text { ACER for } \\
\text { HbA1C reduction } \\
\text { (INR/mg/dl/day) }\end{array}$ \\
\hline MET $(\mathrm{n}=34)$ & 0.7 & 183.8 & $0.2 \pm 0.2$ & $6.0 \pm 2.6$ \\
\hline MET+SU (n=46) & 0.4 & 116.5 & $0.1 \pm 1.1$ & $38.5 \pm 11.9$ \\
\hline MET+SU+AGI (n=24) & 0.2 & 144.5 & $0.9 \pm 1.1$ & $81.2 \pm 26.3$ \\
\hline MET+SU+PIO (n=8) & - & - & $1.3 \pm 0.4$ & $120.8 \pm 53.3$ \\
\hline MET+SU+AGI +DPP-4 I (n=8) & $-5.3^{*}$ & 927.9 & $7.2 \pm 5.95$ & $752.9 \pm 317.2$ \\
\hline MET $(n=34)$ & 0.7 & 183.8 & $0.2 \pm 0.2$ & $6.0 \pm 2.6$ \\
\hline
\end{tabular}

Met-metformin; SU- sulfonylurea; AGI- $\alpha$-glucosidase inhibitor; PIO- pioglitazone; DPP -4 I- dipeptidyl peptidase - 4 inhibitor; *Negativ value indicates either the drug is more expensive or more effective than best treatment.

Among the co-morbidities $(n=249)$, dyslipidemia $(n=87)$ was most common followed by systemic hypertension $(n=73)$, coronary artery disease $(n=43)$ and hypothyroidism $(\mathrm{n}=15)$. Co-prescribed medications included hypolipidemic agents $(n=90)$, antiplatelet agents $(n=62)$, angiotensin receptor blockers $(n=49)$, multivitamin $(n=44)$, beta blockers $(n=24)$, thyroxine $(n=17)$ calcium channel blockers $(n=13)$, diuretics $(n=10)$, ACE inhibitors $(n=7)$, proton pump inhibitors $(n=7)$, respiratory medications $(n=5)$, iron and calcium $(n=3)$ and other medications $(n=13)$. 
Atorvastatin $(n=69)$, low dose aspirin $(n=55)$ were the frequently co-prescribed medications.

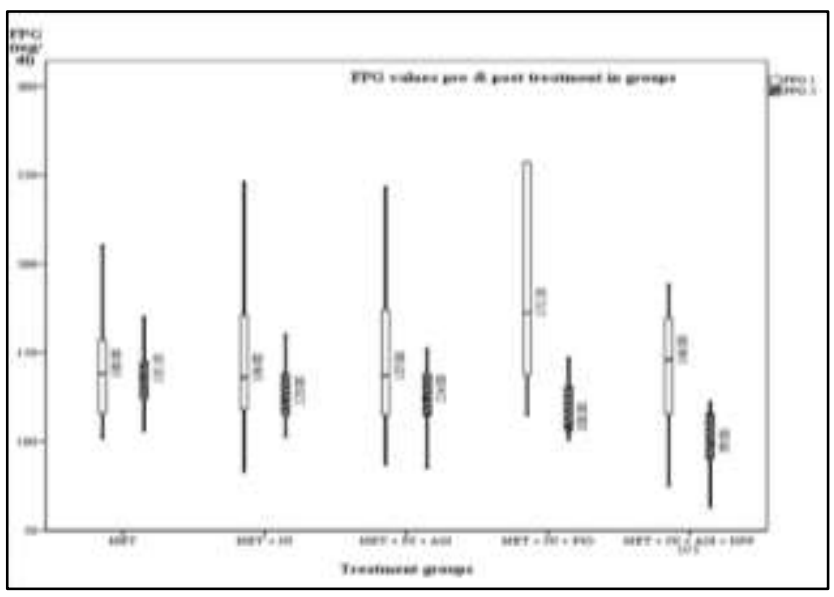

Figure 1: Box and whisker plot showing pre-treatment and post-treatment FPG in treatment groups.

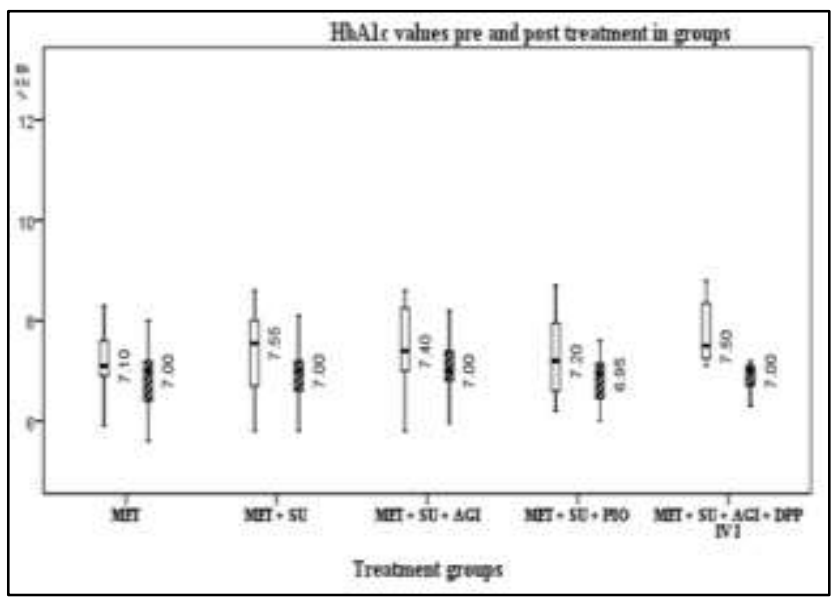

Figure 2: Box and whisker plot showing pre-treatment and post-treatment $\mathrm{HbA1C}$ in treatment groups.

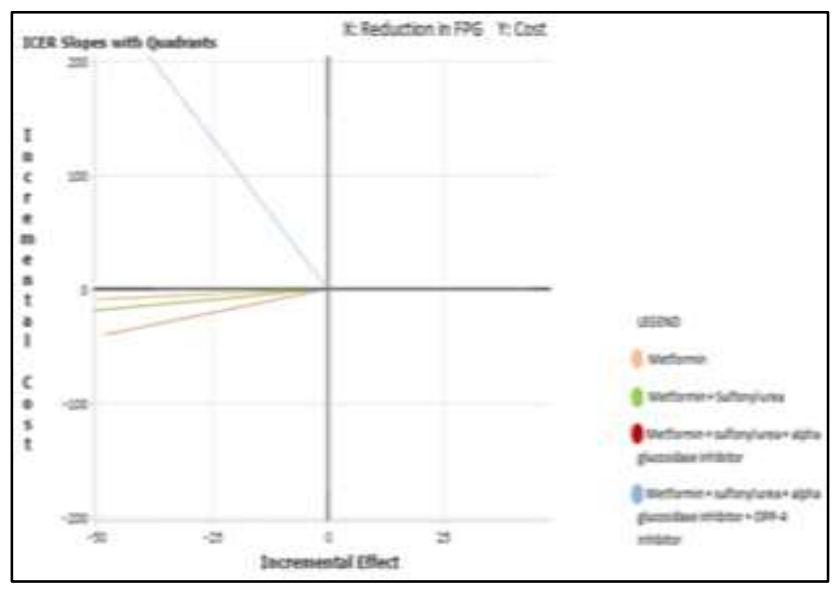

Figure 3: ICER plot for different treatment regimens in reducing FPG.

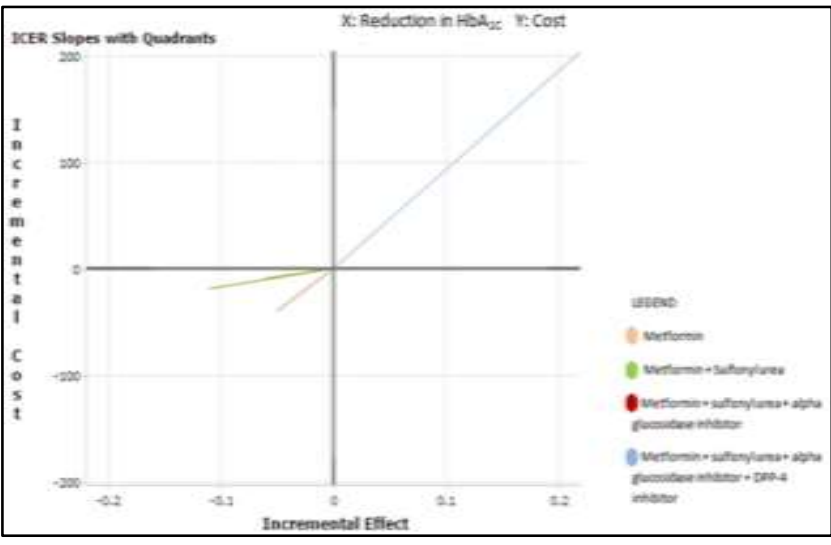

Figure 4: ICER plot for different treatment regimens in reducing FPG.

WHO drug use indicators were

- Encounter with an antibiotic prescribed - 5.3\%

- Encounter with an injection prescribed - 8\%

- Percentage of drugs prescribed by generic name - $5.3 \%$

- Percentage of patients treated without drugs-Nil

Average drug cost per encounter $\sim 9$ INR

\section{DISCUSSION}

In our study, mean age and duration of diabetes was lower than previous reports from Kerala. ${ }^{9}$ Probably due to increasing literacy rate and awareness among Keralites motivating them to seek early medical attention. The prevalence of diabetes was slightly higher in females in contrast to the national average. ${ }^{10}$ The BMI of both males and females were in the overweight range for Asians. ${ }^{11}$ and was higher than a previous study. ${ }^{12}$ There was high prevalence of comorbidities, dyslipidemia $(n=87)$, systemic hypertension $(n=73)$, coronary artery disease $(\mathrm{n}=43)$ and hypothyroidism $(\mathrm{n}=15)$ similar to previous surveys. ${ }^{9}$ The Asian Indian Phenotype. ${ }^{13}$ Have an innate increased risk of these co-morbidities. These comorbidities are also attributable to changing lifestyle habits such as sedentarism, fast food culture, which can be modified. $10 \%(\mathrm{n}=15)$ prevalence of hypothyroidism was observed similar to previous reports. ${ }^{14}$

Prescription analysis showed a higher rate of prescription of metformin $(n=143)$ due to its effective glycemic control without hypoglycaemia, low cost, weight loss, reduction of insulin resistance and compliance of treating physicians to treatment guidelines. Among sulfonylureas there is an increase in rate of prescription of glimepiride $(n=73)$ since recent evidence suggest its favourable pleiotropic effects, cardiovascular beneficial effects and low incidence of hypoglycemia. ${ }^{15}$ Glimepiride has been advocated as the sulfonylurea of choice in obese diabetics and south Asians. ${ }^{16}$ Reduction in rate of prescription of glibenclamide $(n=16)$ can be due to its higher incidence of hypoglycaemia and cardiovascular mortality on long term use. $^{15,17}$ Voglibose, which was approved a decade ago, 
was prescribed for 41 patients and vildagliptin the newest and expensive agent was prescribed for 23 patients. $\alpha$ glucosidase inhibitors provide adequate post prandial glycemic control among oral antidiabetic agents. Of which voglibose is the well tolerated and an efficacious agent which could be the reason for its high rates of prescription. Acarbose $(n=1)$ and miglitol use was minimal owing to its gastrointestinal adverse effects such as flatulence, diarrhea and abdominal discomfort. DPP-4 inhibitors $(n=24)$ have been advocated as second line agents due to its improved glycemic control over time, pleiotropic cardiovascular effects and pancreatic beta cell protective effects in animal studies. ${ }^{18,19}$ Pioglitazone $(n=16)$ prescription has declined in our study compared to the recent trend. ${ }^{20}$ and was not used as monotherapy agent. This could be the repercussion of the ban and subsequent revoking of the ban and recent black box warning of pioglitazone as an agent causing increased risk of bladder carcinoma. ${ }^{21}$ Combination therapy in T2DM is justifiable and often required for better glycemic control and for reducing adverse effects of individual agents. In our study, combination therapy was advocated for 111 patients, most common being metformin sulfonylurea combination $(n=46)$. The rationale being, metformin reduces hepatic gluconeogenesis and decreases insulin resistance while sulfonylurea increases insulin secretions, which counter the two major pathologies in T2DM. ${ }^{22}$

Drug utilization showed an increase in utilization of metformin, glimepiride and a reduction in utilization of glibenclamide in contrast to earlier reports where glibenclamide was most utilized. ${ }^{6}$ This is due to adherence to changing treatment guidelines, metformin's ability to reduce insulin resistance and weight without causing hypoglycemia. ${ }^{23,24}$ On the other hand there is increased risk of hypoglycaemia, cardiovascular mortality and beta cell fatigue with long term use of glibenclamide. ${ }^{19,25}$ Glimepiride on the other hand has favourable pleiotropic cardiovascular effects, low incidence of hypoglycaemia and is the preferred sulfonylurea in obese patients. ${ }^{26-28}$

Analysing FPG and $\mathrm{HbA} 1 \mathrm{C}$ values, pre-treatment and 1 year post treatment of 5 commonly prescribed treatment groups showed that all treatment regimens showed significant reduction in FPG except metformin monotherapy. Fasting plasma glucose is a highly unreliable value for assessing glycemic control since it is dependent on previous day's diet, medication and exercise. All treatment groups except metformin sulfonylurea pioglitazone combination showed significant reduction of $\mathrm{HbA} 1 \mathrm{C}$. This may be explained on the basis of significantly longer duration of diabetes in this group, since efficacy of oral antidiabetic agents decrease as diabetes progresses. ${ }^{19,25}$ The average cost of oral antidiabetic agents per year was $\sim 5000$ INR. Costeffectiveness analysis showed metformin as the most economical therapy, which produced significant reduction in $\mathrm{HbA} 1 \mathrm{C}$. Since there was no significant difference in reduction of $\mathrm{HbA} 1 \mathrm{C}$ between groups, reduction in FPG was considered the parameter for selecting most effective therapy which was metformin sulfonylurea pioglitazone combination. Incremental cost-effectiveness ratio when calculated with the most economic treatment showed an additional expenditure of $\sim 60$ paisa per day for $1 \mathrm{mg} / \mathrm{dl}$ reduction of FPG and $\sim 183$ INR per day for $1 \%$ reduction of HbA1C. When analysed with the most frequently prescribed treatment regimen (metformin sulfonylurea combination), extra expenditure of 35 paisa per day for $1 \mathrm{mg} / \mathrm{dl}$ reduction of FPG and 113 INR per day for $1 \%$ reduction of $\mathrm{HbA} 1 \mathrm{C}$ was seen. ICER showed metformin sulfonylurea $\alpha$-glucosidase inhibitor DPP-4 inhibitor combination as more effective and more expensive in reducing $\mathrm{HbA} 1 \mathrm{C}$.

Out of the total expenditure of $\sim 9000$ INR per year INR 4300 was for co-prescribed medications. This increased expenditure in health care industry is partly due to prescription of expensive treatments and partly due to modifiable risk factors which causes morbidity. Mean cost per prescription was $\sim 9$ INR. Among co-prescribed medications hypolipidemic agents $(n=90)$ were most prescribed owing to the higher incidence of dyslipidemia. Antiplatelet agents $(n=62)$, drugs acting on RAAS $(n=56)$, multivitamin $(n=44)$, beta blockers $(n=24)$, thyroxine $(n=17)$, calcium channel blockers $(n=13)$ and diuretics $(n=10)$ were also used. These are corresponding to the comorbidities, highest being dyslipidemia and hypertension which were similar to previous studies.9. $76 \%$ of patients with dyslipidemia were prescribed atorvastatin and $21.1 \%$ rosuvastatin, though rosuvastatin is more potent, economical and alteration produced in $\mathrm{HbA} 1 \mathrm{C}$ is less compared to atorvastatin. ${ }^{29,30}$ Angiotensin receptor blockers $(n=49)$, beta blockers $(n=24)$, calcium channel blockers $(n=13)$, diuretics $(n=10)$ and ACE inhibitors $(n=7)$ were the antihypertensive used. The high frequency of prescription of drugs acting on RAAS might be due to cardioprotective and renoprotective effects of these drugs in diabetic hypertensive. Thiazide diuretics in optimal doses were prescribed to eight patients as add on therapy. These agents are preferred in low doses for diabetic hypertensives. ${ }^{31}$ due to its lower propensity to producing metabolic effects. Cardio selective beta blockers were prescribed for control of hypertension in 24 patients. This cannot be considered judicious although there is increased avocations of its use in diabetics. ${ }^{32}$ as they are contraindicated in patients with hypoglycemic episodes and hypoglycemic unawareness and theoretically they produce hyperglycemia, alter insulin sensitivity and lipid profile. ${ }^{33,34}$ Most commonly used antiplatelet agent was low dose aspirin which is consistent with current trend. The drug combinations used for treatment of diabetes and co-morbidities were appropriate. Encounters with antibiotic prescribed was $5.3 \%$ which was higher than a previous study and with injections prescribed was $8.7 \%$ which showed lower value than previous study. ${ }^{6}$ Only $5.3 \%$ prescriptions were generic which implies the need for generic prescriptions. 
A limitation of this study was small sample size and baseline variability is the limitations of our study. A further study with analysis of post prandial blood glucose is required since it is a better predictor of cardiovascular complications of diabetes.

\section{CONCLUSION}

High prescription rates of metformin were due to its action on insulin resistance and weight. Addition of pioglitazone was cost effective and DPP-4 inhibitor was expensive but effective.

\section{Funding: No funding sources}

Conflict of interest: None declared

Ethical approval: The study was approved by the Institutional Ethics Committee

\section{REFERENCES}

1. Akter S, Rahman MM, Abe SK, Sultana P. Prevalence of diabetes and prediabetes and their risk factors among Bangladeshi adults: a nationwide survey. Bull World Health Organ. 2014;92(3):204-13

2. IDF Diabetes Atlas, $6^{\text {th }}$ edi. Brussels, Belgium: international diabetes federation; 2013.

3. Mohan V, Sandeep S, Deepa R, Shah B, Varghese C. Epidemiology of type 2 diabetes: Indian scenario. Indian J Med Res. 2007;125(3):217-30.

4. Kutty VR, Joseph A, Soman CR. High prevalence of type 2 diabetes in an urban settlement in Kerala, India. Ethn Health. 1999;4(4):231-9.

5. Strom BL. Pharmacoepidemiology. $4^{\text {th }}$ edi. John Wiley and Sons; 2006;3-17.

6. Sutharson L, Hariharan RS, Vamsadhara C. Drug utilization study in diabetology outpatient setting of a tertiary hospital. Indian J Pharmacol. 2003;35(4):237-40.

7. Merlo J, Wessling A, Melander A. Comparison of dose standard units for drug utilisation studies. Eur J Clin Pharmacol. 1996;50(1-2):27-30.

8. Gafni A, Birch S. Incremental cost-effectiveness ratios (ICERs): The silence of the lambda. Soc Sci Med. 2006;62(9):2091-100.

9. Menon VU, Guruprasad U, Sundaram KR, Jayakumar RV, Nair V, Kumar H. Glycaemic status and prevalence of comorbid conditions among people with diabetes in Kerala. Natl Med $\mathbf{J}$ India. 2008;21(3):112-5.

10. Anjana RM, Pradeepa R, Deepa M, Datta M, Sudha V, Unnikrishnan R, et al. Prevalence of diabetes and prediabetes (impaired fasting glucose and/or impaired glucose tolerance) in urban and rural India: Phase I results of the Indian Council of Medical ResearchIndia Diabetes (ICMR-INDIAB) study. Diabetologia. 2011;54(12):3022-7.

11. WHO EC. Appropriate body-mass index for Asian populations and its implications for policy and intervention strategies. Lancet. 2004;363(9403):157.
12. Tiwari RR, Deb PK, Debbarma A, Chaudhuri R, Chakraborti A, Lepcha M, et al. Risk factor analysis in self-reported diabetes in a rural Kerala population. Int J Diabetes Dev Ctries. 2008;28(3):91-4.

13. Joshi SR. Type 2 diabetes in Asian Indians. Clin Lab Med. 2012;32(2):207-16.

14. Unnikrishnan AG, Kalra S, Sahay RK, Bantwal G, John M, Tewari N. Prevalence of hypothyroidism in adults: An epidemiological study in eight cities of India. Indian J Endocrinol Metab. 2013;17(4):647-52.

15. Glyburide, gliclazide or glimepiride for elderly patients with type 2 diabetes: a review of the clinical effectiveness and safety-an update. Ottawa (ON): Canadian agency for drugs and technologies in health; $2015 . \quad$ Available at http://www.ncbi.nlm.nih.gov/books/NBK315876/. Accessed 2015.

16. Kalra S, Aamir AH, Raza A, Das AK, Khan A, Shrestha D, et al. Place of sulfonylureas in the management of type 2 diabetes mellitus in South Asia: A consensus statement. Indian J Endocrinol Metab. 2015;19(5):577-96.

17. Simpson SH, Lee J, Choi S, Vandermeer B, Abdelmoneim AS, Featherstone TR. Mortality risk among sulfonylureas: a systematic review and network meta-analysis. Lancet Diabetes Endocrinol. 2015;3(1):43-51.

18. Fisman EZ, Tenenbaum A. Antidiabetic treatment with gliptins: focus on cardiovascular effects and outcomes. Cardiovasc Diabetol. 2015;14(1):129.

19. Wajchenberg BL. beta-cell failure in diabetes and preservation by clinical treatment. Endocr Rev. 2007;28(2):187-218.

20. Hashim S, Gomes T, Juurlink D, Hellings C, Mamdani M. The rise and fall of the thiazolidinediones: impact of clinical evidence publication and formulary change on the prescription incidence of thiazolidinediones. J Popul Ther Clin Pharmacol J Thérapeutique Popul Pharamcologie Clin. 2013;20(3):e238-42.

21. Zhu Z, Shen Z, Lu Y, Zhong S, Xu C. Increased risk of bladder cancer with pioglitazone therapy in patients with diabetes: a meta-analysis. Diabetes Res Clin Pract. 2012;98(1):159-63.

22. Hermann LS. Biguanides and sulfonylureas as combination therapy in NIDDM. Diabetes Care. 1990;13(S3):37-41.

23. Giannarelli R, Aragona M, Coppelli A, Del Prato S. Reducing insulin resistance with metformin: the evidence today. Diabetes Metab. 2003;29(4Pt2):6S:28-35.

24. Levri KM, Slaymaker E, Last A, Yeh J, Ference J, D'Amico F, et al. Metformin as treatment for overweight and obese adults: a systematic review. Ann Fam Med. 2005;3(5):457-61.

25. Inzucchi SE. Oral antihyperglycemic therapy for type 2 diabetes: scientific review. Jama. 2002;287(3):360-72.

26. Inukai $\mathrm{K}$, Watanabe $\mathrm{M}$, Nakashima $\mathrm{Y}$, Takata $\mathrm{N}$, Isoyama A, Sawa $\mathrm{T}$, et al. Glimepiride enhances 
intrinsic peroxisome proliferator-activated receptorgamma activity in 3T3-L1 adipocytes. Biochem Biophys Res Commun. 2005;328(2):484-90.

27. Holstein A, Plaschke A, Egberts EH. Lower incidence of severe hypoglycaemia in patients with type 2 diabetes treated with glimepiride versus glibenclamide. Diabetes Metab Res Rev. 2001;17(6):467-73.

28. Basit A, Riaz M, Fawwad A. Glimepiride: evidencebased facts, trends, and observations. Vasc Health Risk Manag. 2012;8:463-72.

29. Her AY, Kim JY, Kang SM, Choi D, Jang Y, Chung $\mathrm{N}$, et al. Effects of atorvastatin $20 \mathrm{mg}$, rosuvastatin $10 \mathrm{mg}$, and atorvastatin/ezetimibe $5 \mathrm{mg} / 5 \mathrm{mg}$ on lipoproteins and glucose metabolism. J Cardiovasc Pharmacol Ther. 2010;15(2):167-74.

30. Simsek S, Schalkwijk CG, Wolffenbuttel BHR. Effects of rosuvastatin and atorvastatin on glycaemic control in Type 2 diabetes the CORALL study. Diabet Med J Br Diabet Assoc. 2012;29(5):628-31.
31. Patel BM, Mehta AA. Choice of anti-hypertensive agents in diabetic subjects. Diab Vasc Dis Res. 2013;10(5):385-96.

32. Cruickshank JM. Beta-blockers and diabetes: the bad guys come good. Cardiovasc Drugs Ther Spons Int Soc Cardiovasc Pharmacother. 2002;16(5):457-70.

33. Mills GA, Horn JR. Beta-blockers and glucose control. Drug Intell Clin Pharm. 1985;19(4):246-51.

34. Herink M, Ito MK. Medication induced changes in lipid and lipoproteins. In: De Groot LJ, Beck-Peccoz P, Chrousos G, Dungan K, Grossman A, Hershman JM, et al., editors. Endotext. South Dartmouth (MA); MDText.com, Inc.; 2000. Available at http://www.ncbi.nlm.nih.gov/books/NBK326739/. Accessed 2000.

35. Goldner MG, Zarowitz H, Akgun S. Hyperglycemia and glycosuria due to thiazide derivatives administered in diabetes mellitus. $\mathrm{N}$ Engl $\mathrm{J}$ Med. 1960;262:403-5.

36. Christlieb AR. The hypertensions of diabetes. Diabetes Care. 1982;5(1):50-8.

Cite this article as: George N, Kumar PVA, Amma VS. Glycemic control and costeffectiveness attained by the drug utilization of oral antidiabetic agents in a tertiary care hospital in South India. Int J Basic Clin Pharmacol 2016;5:684-91. 